\title{
Prevalence of Vitamin D Deficiency among Patients of Acute Coronary Syndrome in a Tertiary Care Center of Eastern Nepal
}

\author{
Richa Nepal, ' Prahlad Karki,' Surendra Uraw, ' Madhab Lamsal ${ }^{2}$ \\ 'Department of Internal Medicine, B.P. Koirala Institute of Health Sciences, Dharan, Nepal, \\ ${ }^{2}$ Department of Biochemistry, B.P. Koirala Institute of Health Sciences, Dharan, Nepal.
}

\section{ABSTRACT}

Introduction: Vitamin D deficiency is an emerging risk factor for cardiovascular diseases. Very few studies have been done to find out vitamin D deficiency status among cardiovascular patients in Nepalese setup. This research aims to find out the prevalence of vitamin D deficiency among patients of acute coronary syndrome admitted in a tertiary care center of eastern Nepal.

Methods: This was a descriptive cross-sectional study conducted among patients of acute coronary syndrome admitted in a tertiary care hospital from 1st February 2018 to 31st July 2018. Ethical clearence was taken from Institutional Review Committee of B.P. Koirala Institute of Health Sciences (Reference number: 259/074/075-IRC). Convenience sampling method was used. Data was entered in Microsoft Excel and analyzed using Statistical Package for the Social Sciences version 25. Point estimate at 95\% Confidence Interval was calculated along with frequency and proportion for binary data.

Results: A total of 33 (64.7\%) at 95\% Confidence Interval (51.58-77.82) patients of acute coronary syndrome had vitamin D deficiency in our study with 19 (37.3\%) having mild deficiency and 14 $(27.4 \%)$ having moderate deficiency. None of the patients had severe vitamin D deficiency in our study. The mean vitamin D levels were lower in diabetics $(23.57 \pm 9.28 \mathrm{ng} / \mathrm{ml})$ as compared to nondiabetics $(31.91 \pm 12.50 \mathrm{ng} / \mathrm{ml})$, in hypertensive patients $(24.36 \pm 7.67 \mathrm{ng} / \mathrm{ml})$ as compared to nonhypertensive patients $(30.97 \pm 13.72 \mathrm{ng} / \mathrm{ml})$, and in patients with dyslipidemia $(22.86 \pm 6.44 \mathrm{ng} / \mathrm{ml})$ as compared to those without dyslipidemia $(37.68 \pm 13.15 \mathrm{ng} / \mathrm{ml})$.

Conclusions: Prevalence of vitamin D deficiency among patients of acute coronary syndrome in our study was comparable to various other homologous international studies.

Keywords: acute coronary syndrome; myocardial infarction; prevalence; vitamin D.

\section{INTRODUCTION}

A growing body of evidence has linked inadequate vitamin $D$ levels to major non-skeletal diseases, especially cardiovascular diseases. ${ }^{1}$ Acute coronary syndrome (ACS) is one of the leading cardiovascular diseases, to cause significant morbidity and mortality in patients. It has been associated with various modifiable and non-modifiable risk factors, out of which vitamin $D$ deficiency is the novel risk factor with potential therapeutic implications. ${ }^{2}$

Observational studies have associated chronic vitamin
D deficiency to classical cardiovascular risk factors like hypertension, diabetes mellitus, dyslipidemia and metabolic syndrome. ${ }^{3}$ The prevalence of vitamin $D$ deficiency ranged from 80 to $95 \%$ in patients of coronary artery disease in studies, done in different parts of the world. ${ }^{4-5}$ Data related to vitamin D deficiency, in patients with cardiovascular diseases, is very limited in Nepalese setup.

Correspondence: Dr. Richa Nepal, Department of Internal Medicine, B.P. Koirala Institute of Health Sciences, Dharan, Nepal. Email: nepaldeepika123@gmail.com, Phone: +977-9860236283. 
This research aims to find out the prevalence of vitamin D deficiency among patients of acute coronary syndrome,admitted in a tertiary care center of eastern Nepal.

\section{METHODS}

This was a descriptive cross-sectional study conducted over a span of six months from $1^{\text {st }}$ February, 2018 till $31^{\text {st }}$ July, 2018. The study was conducted in B.P. Koirala Institute of Health Sciences (BPKIHS) which is the tertiary care center located in eastern Nepal. The Institutional Review Committee (IRC) of BPKIHS had approved our protocol prior to starting the study (reference number: 259/074/075-IRC). All the consecutive patients, presenting to BPKIHS emergency during the study period, who were diagnosed to have acute coronary syndrome, were included in this study. Patients who were on vitamin D supplement or on any other medications, which interfered with vitamin D levels, were excluded from this study. These medications included glucocorticoids, anti-epileptics like phenytoin, phenobarbital, and carbamazepine, antiretroviral drugs and anti-tubercular drugs like rifampicin. Similarly, patients of chronic kidney disease, chronic liver disease and parathyroid related endocrine disorders were also excluded. Patients were included in this study, only after they gave written consent for history taking, physical examination, and necessary investigations. All the consecutive patients of acute coronary syndrome were included in this study after the inclusion and exclusion criteria were taken into account. The sample size was calculated using the formula,

$$
\begin{aligned}
n & =Z^{2} \times p \times q / e^{2} \\
& =(1.645)^{2} \times(0.835) \times(1-0.835) /(0.09)^{2} \\
& =46
\end{aligned}
$$

\section{Where,}

$\mathrm{n}=$ required sample size,

$Z=1.645$ at $90 \%$ Confidence Interval

$\mathrm{p}=$ prevalence of vitamin D deficiency among patients of ACS in reference population, $83.5 \%{ }^{4}$

$q=1-p$

$\mathrm{e}=$ margin of error, $9 \%$

Hence, the calculated sample size was 46 . Taking a $10 \%$ non-response rate, we included 51 participants in the study.

Data was collected on a structured questionnaire, which included questions on demographic variables and relevant clinical history. Detailed clinical examination was done and diagnosis of acute coronary syndrome was made based on clinical history, ECG findings and raised levels of cardiac biomarkers during admission. Cases of unstable angina, non-ST elevated myocardial infarction, and ST elevated myocardial infarction were all included. Blood samples for relevant baseline investigations were collected at the time of admission. Sample for lipid profile and vitamin D was drawn after eight hours of fasting on the next day of admission from BPKIHS ward and coronary care unit. Patients were diagnosed to have dyslipidemia as per National Cholesterol Education Program Adult Treatment Panel (NCEP ATP III) guidelines. Following clinical stability, as the patients were allowed to be mobilized, body mass index (BMI) was calculated.

Laboratory estimation of vitamin D level was done on Maglumi fully-autochemiluminescence immunoassay (CLIA) analyzer in the Department of Biochemistry of BPKIHS. Two milliliters of blood was centrifuged at room temperature. The collected serum was incubated twice, after which the washed sample underwent chemiluminescent reaction to measure relative light units (RLU) that gave the measure of 25-OH-vitamin D in serum. Vitamin D level of $20-29 \mathrm{ng} / \mathrm{ml}$ was considered as insufficiency (also termed as mild deficiency), 10 to $19 \mathrm{ng} / \mathrm{ml}$ was considered as moderate deficiency, and less than $10 \mathrm{ng} / \mathrm{ml}$ was considered as severe deficiency, according to BPKIHS biochemistry laboratory values.

Data was entered in an excel sheet and analyzed by IBM Statistical Package for the Social Sciences version 25. Descriptive statistics were presented with frequencies and percentages for categorical variables, and mean along with standard deviation for continuous variables.

\section{RESULTS}

A total of 51 patients of acute coronary syndrome were enrolled in this study out of which 33 (64.7\%) (51.5877.82 at $95 \% \mathrm{Cl}$ ) patients of acute coronary syndrome had vitamin D deficiency (Figure 1).

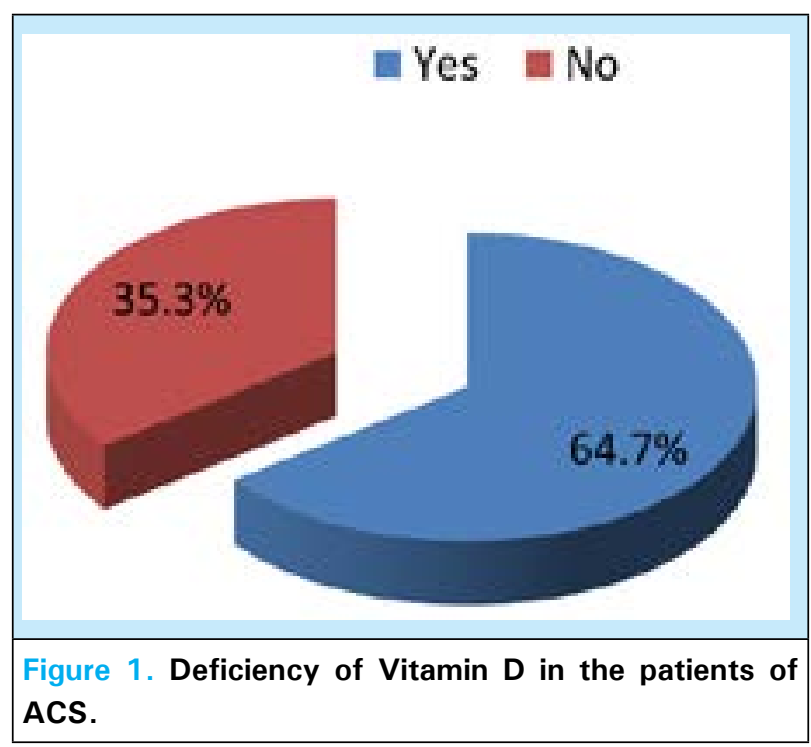


Nepal et al. Prevalence of Vitamin D Deficiency among Patients of Acute Coronary Syndrome in a Tertiary Care Center...

Out of the vitamin D deficient patients, 19 (37.3\%) had mild deficiency and $14(27.4 \%)$ had moderate deficiency (Table 1).

Table 1. Vitamin D levels in the patients of ACS.

\begin{tabular}{|ll|}
\hline \multicolumn{1}{|c}{ Vitamin D levels } & \multicolumn{1}{|c|}{$\begin{array}{c}\text { Frequency } \\
\mathbf{n}(\%)\end{array}$} \\
$\begin{array}{ll}10 \mathrm{ng} / \mathrm{ml} \text { to } 19 \mathrm{ng} / \mathrm{ml} \text { (Moderate } \\
\text { deficiency) }\end{array}$ & $14(27.4)$ \\
$20 \mathrm{ng} / \mathrm{ml}$ to $29 \mathrm{ng} / \mathrm{ml}$ (Mild deficiency) & $19(37.3)$ \\
$30 \mathrm{ng} / \mathrm{ml}$ and more (Normal value) & $18(35.3)$ \\
\hline
\end{tabular}

The mean age of the patients was $61.7 \pm 11.70$ years. Out of total patients, 33 (64.7\%) were of age 60 years and above, and 18 (35.3\%) were females. Around 41 $(80 \%)$ patients were from terai region of Nepal, 17 $(33 \%)$ patients consumed vegetarian diet and 24 (47\%) of them were engaged in occupation that involved outdoor activities. Twenty-four (47\%) of them were diabetic, 23 (45\%) were hypertensive, 20 (39\%) were obese with body mass index of $\geq 25 \mathrm{~kg} / \mathrm{m}^{2}$, and 32 $(62.7 \%)$ were smokers. Around 33 (64.7\%) patients had some form of dyslipidemia on evaluation (Table 2).

\begin{tabular}{|c|c|c|}
\hline Variables & Category & n (\%) \\
\hline \multirow[t]{2}{*}{ Age } & $<60$ years & $18(35.3)$ \\
\hline & $\geq 60$ years & $33(64.7)$ \\
\hline \multirow[t]{2}{*}{ Gender } & Female & 18 (35.3) \\
\hline & Male & $33(64.7)$ \\
\hline \multirow[t]{2}{*}{ Address } & Terai & $41(80.4)$ \\
\hline & Hilly & $10(19.6)$ \\
\hline \multirow[t]{2}{*}{ Occupation } & Indoors & $27(52.9)$ \\
\hline & Outdoors & $24(47.1)$ \\
\hline \multirow{2}{*}{$\begin{array}{l}\text { Diabetes } \\
\text { mellitus }\end{array}$} & Yes & $24(47.05)$ \\
\hline & No & $27(52.95)$ \\
\hline \multirow[t]{2}{*}{ Hypertension } & Yes & $23(45.09)$ \\
\hline & No & $28(54.91)$ \\
\hline
\end{tabular}

\begin{tabular}{|c|c|c|}
\hline \multirow[t]{3}{*}{ Active Smoker } & Yes & $32(62.7)$ \\
\hline & No & 19 (37.3) \\
\hline & $\begin{array}{l}\text { Underweight } \\
\left(<18.5 \mathrm{~kg} / \mathrm{m}^{2}\right)\end{array}$ & $6(11.76)$ \\
\hline \multirow[t]{4}{*}{$\begin{array}{l}\text { Body mass } \\
\text { index (BMI) }\end{array}$} & $\begin{array}{l}\text { Normal }(18.5- \\
\left.24.9 \mathrm{~kg} / \mathrm{m}^{2}\right)\end{array}$ & $25(49.01)$ \\
\hline & $\begin{array}{c}\text { Overweight (25- } \\
29.9 \mathrm{~kg} / \mathrm{m} 2)\end{array}$ & $15(29.41)$ \\
\hline & $\begin{array}{l}\text { Class I Obesity } \\
\left(30-34.5 \mathrm{~kg} / \mathrm{m}^{2}\right)\end{array}$ & $2(3.92)$ \\
\hline & $\begin{array}{l}\text { Class } 2 \text { Obesity } \\
\left(35-39.9 \mathrm{~kg} / \mathrm{m}^{2}\right)\end{array}$ & $3(5.88)$ \\
\hline \multirow[t]{2}{*}{ Diet } & Vegetarian & $17(33.3)$ \\
\hline & Mixed & $34(66.7)$ \\
\hline \multirow[t]{2}{*}{ Dyslipidemia } & Present & $33(64.7)$ \\
\hline & Absent & $18(35.3)$ \\
\hline
\end{tabular}

According to our lab reference values, 19 (37.3\%) patients had mild vitamin D deficiency and 14 (27.4\%) patients had moderate vitamin D deficiency. None of the patients had severe vitamin $D$ deficiency in our study. The mean vitamin D level was $27.99 \pm 11.77 \mathrm{ng} / \mathrm{ml}$ with the minimum value of $15.82 \mathrm{ng} / \mathrm{ml}$ and maximum value of $64.53 \mathrm{ng} / \mathrm{ml}$. Mean vitamin D levels and vitamin D deficiency status of the study population, stratified on the basis of baseline characteristics (Table 3 ). The mean vitamin $D$ levels were found to be lower in females $(21.62 \pm 6.81 \mathrm{ng} / \mathrm{ml})$ as compared to males $(31.46 \pm 12.51 \mathrm{ng} / \mathrm{ml})$, in patients of age group $\geq 60$ years $(25.71 \pm 8.75 \mathrm{ng} / \mathrm{ml})$ as compared to patients of $<60$ years $(32.17 \pm 15.32 \mathrm{ng} / \mathrm{ml})$, and in patients from hilly region $(22.03 \pm 5.37 \mathrm{ng} / \mathrm{ml})$ as compared to terai region $(29.44 \pm 12.48 \mathrm{ng} / \mathrm{ml})$ of Nepal. Similarly, the mean vitamin $D$ level was also found to be lower in diabetic $(23.57 \pm 9.28 \mathrm{ng} / \mathrm{ml})$ as compared to non-diabetic patients with ACS $(31.91 \pm 12.50 \mathrm{ng} / \mathrm{ml})$. Hypertensive patients had lower mean vitamin D level $(24.36 \pm 7.67 \mathrm{ng} / \mathrm{ml})$ as compared to non-hypertensive patients $(30.97 \pm 13.72 \mathrm{ng} / \mathrm{ml})$ in our study. Likewise, patients of ACS with dyslipidemia had lower mean vitamin D level $(22.86 \pm 6.44 \mathrm{ng} / \mathrm{ml})$ than those without dyslipidemia $(37.68 \pm 13.15 \mathrm{ng} / \mathrm{ml})$ (Table 3). 


\begin{tabular}{|c|c|c|c|c|c|}
\hline \multirow{2}{*}{ Baseline characteristics } & \multirow[b]{3}{*}{ Female } & \multirow{2}{*}{ Frequency n (\%) } & \multirow{2}{*}{$\begin{array}{l}\text { Vitamin D (ng/ml) } \\
\text { Mean } \pm \text { SD* }\end{array}$} & \multicolumn{2}{|c|}{ Vitamin D deficiency status } \\
\hline & & & & Yes n (\%) & No $n(\%)$ \\
\hline \multirow[t]{2}{*}{ Gender } & & $18(35.3)$ & $21.62 \pm 6.81$ & $16(31.4)$ & $2(3.9)$ \\
\hline & Male & $33(64.7)$ & $31.46 \pm 12.51$ & $17(33.3)$ & $16(31.4)$ \\
\hline \multirow[t]{2}{*}{ Age } & $<60$ yrs & $18(35.3)$ & $32.17 \pm 15.32$ & $10(19.6)$ & $8(15.7)$ \\
\hline & $\geq 60 \mathrm{yrs}$ & $33(64.7)$ & $25.71 \pm 8.75$ & $23(45.1)$ & $10(19.6)$ \\
\hline \multirow[t]{2}{*}{ Address } & Terai & $41(80.4)$ & $29.44 \pm 12.48$ & $24(47.1)$ & $17(33.3)$ \\
\hline & Hilly & $10(19.6)$ & $22.03 \pm 5.37$ & $9(17.6)$ & $1(2.0)$ \\
\hline \multirow[t]{2}{*}{ Diet } & Vegetarian & $17(33.3)$ & $26.51 \pm 10.58$ & $12(23.5)$ & $5(9.8)$ \\
\hline & Mixed & $34(66.7)$ & $28.73 \pm 12.41$ & $21(41.2)$ & $13(25.5)$ \\
\hline \multirow[t]{2}{*}{ Diabetes Mellitus } & Yes & $24(47.1)$ & $23.57 \pm 9.28$ & $19(37.3)$ & $5(9.8)$ \\
\hline & No & $27(52.9)$ & $31.91 \pm 12.50$ & $14(27.5)$ & $13(25.4)$ \\
\hline \multirow[t]{2}{*}{ Hypertension } & Yes & $23(45.1)$ & $24.36 \pm 7.67$ & $17(33.3)$ & $6(11.8)$ \\
\hline & No & $28(54.9)$ & $30.97 \pm 13.72$ & $16(31.4)$ & $12(23.5)$ \\
\hline \multirow[t]{2}{*}{ Obesity } & Yes & $20(39.2)$ & $25.48 \pm 7.64$ & $15(29.4)$ & $5(9.8)$ \\
\hline & No & $31(60.8)$ & $22.70 \pm 6.56$ & $18(35.3)$ & $13(25.5)$ \\
\hline \multirow[t]{2}{*}{ Dyslipidemia } & Yes & $33(64.7)$ & $22.86 \pm 6.44$ & $28(54.9)$ & $5(9.8)$ \\
\hline & No & $18(35.3)$ & $37.68 \pm 13.15$ & $5(9.8)$ & $13(25.5)$ \\
\hline \multirow[t]{2}{*}{ Smoking } & Yes & $32(62.7)$ & $29.82 \pm 13.50$ & $18(35.3)$ & $14(27.4)$ \\
\hline & No & $19(37.3)$ & $24.90 \pm 7.42$ & $15(29.4)$ & $4(7.9)$ \\
\hline
\end{tabular}

*SD - standard deviation.

\section{DISCUSSION}

Deficiency of vitamin D, also known as 'sunshine vitamin', is a common health problem, very often unrecognized and untreated. Classically, vitamin D deficiency has been known to cause growth retardation, rickets, and dental caries in children, and osteomalacia, osteopenia, and decreased muscle strength in adults. ${ }^{6}$ Apart from role in calcium homeostasis, recent evidences support immunomodulatory effects of vitamin D in human body. ${ }^{7}$ Cardiovascular effects of vitamin D has been hypothesized with demonstration of vitamin D receptors in endothelial cells, lymphocytes, macrophages, cardiomyocytes, vascular smooth muscle cells, and B pancreatic cells. Low vitamin $D$ levels upregulate renin angiotensin aldosterone system (RAAS) and cause endothelial dysfunction to promote atherogenesis. ${ }^{8}$ In a study by Dziedzic et al., lower $25(\mathrm{OH})$ vitamin $D$ levels were found in patients with one to three vessel atherosclerosis as compared to those who did not have significant lesions in their coronary arteries. ${ }^{9}$
High prevalence of vitamin D deficiency has been reported in patients of coronary artery disease in studies conducted in different parts of the world. A study by Akin et al. from Korea concluded that patients with low $25(\mathrm{OH})$ vitamin D levels had higher odds of having significant coronary artery stenosis. ${ }^{10}$ Similarly, prevalence of vitamin D deficiency was reported to be $98.3 \%$ in patients of ACS in a study from New Delhi, India by Roy et al. ${ }^{11}$ Karur et al. concluded that the prevalence of vitamin D deficiency was $83.5 \%$ among patients of acute myocardial infarction in another study from India. ${ }^{4}$ In our study, the prevalence of vitamin D deficiency was $64.7 \%$ (51.58-77.82 at $95 \%$ $\mathrm{Cl}$ ) in patients of acute coronary syndrome. This study adds to the evidence regarding vitamin D status in our context.

In our study, the mean vitamin D levels were found to be lower in female patients and in patients who hailed from hilly region of Nepal (Table 3). Vitamin D insufficiency is known to be associated with indoor lifestyle, sun avoidance strategies, distance from the equator, darker skin and winter season. ${ }^{7}$ Gender wise 
significant difference could be related to the nature of indoor/outdoor activities as defined by classical gender roles of our study population. Similarly, the difference on basis of hills or terai could be related to the degree of sunlight exposure and seasonal variation in these areas.

On stratifying mean vitamin D levels to some prespecified cardiovascular risk factors, mean vitamin D levels were found to be lower in patients with diabetes mellitus, systemic hypertension, and dyslipidemia (Table 3). Similar kind of finding was also seen in the National health and nutritional examination survey done in United States, which showed that the mean $25(\mathrm{OH})$ vitamin D levels were lower in females, in those with history of hypertension, diabetes mellitus or dyslipidemia with $P$ value $<0.001 .{ }^{12}$ Observational studies have recently linked vitamin $D$ levels to factors influencing cardiovascular health; though causal association is yet to be defined. Chronic vitamin D deficiency results in secondary hyperparathyroidism, which eventually has been linked to insulin resistance and development of diabetes mellitus and metabolic syndrome. In a study by Mathieu, et al. administration of $1,25(\mathrm{OH})$ vitamin $\mathrm{D} 3$, prevented the development of type 1 diabetes mellitus in animal models. ${ }^{13}$ Vaidya and Forman reported lower vitamin $D$ levels to be associated to a higher blood pressure and a higher risk of developing systemic hypertension. ${ }^{14}$ In a study by Rejnmark, et al. plasma levels of triglyceride inversely correlated with seasonal change of vitamin D levels. ${ }^{15}$ This finding highlights the influence of vitamin $D$ on plasma lipid profile and cardiovascular health.

Emerging evidence of vitamin $D$ having antiinflammatory, anti-proliferative, anti-diabetic, antihypertrophic and anti-thrombotic effects have intrigued researchers worldwide. While interpreting the findings from our study, it is necessary to consider the prevalence of vitamin $D$ deficiency in general population. Studies from Indian subcontinent countries report prevalence of hypovitaminosis $D$ to range from 70 to $100 \%$ in general population. ${ }^{16}$ Likewise, in a study by Poudel et al., $70 \%$ of total study population who attended outpatient clinic at a tertiary level hospital in Kathmandu, Nepal, had vitamin D deficiency, more commonly found among females and elderlies. ${ }^{17}$ Our study reports high prevalence $(64.7 \%)$ of vitamin D deficiency in patients of acute coronary syndrome with lower mean vitamin D levels in patients with wellknown cardiovascular risk factors like diabetes mellitus, hypertension and dyslipidemia. However, in view of high prevalence of vitamin $D$ deficiency in general population, these findings need to be strengthened with adequately powered randomized controlled trials in future. Until then, possible association or causality can't be proved.

The main limitation of this study was small sample size. Larger well planned studies need to be done to prove causal association of vitamin $D$ to different cardiovascular risk factors. Detailed data, related to diet and skin pigmentation of patients, were not collected, which could have influenced vitamin D levels in our patients.

\section{CONCLUSIONS}

The prevalence of vitamin D deficiency, among patients of acute coronary syndrome in our study, was sufficiently high and comparable to various other homologous studies done in the past. The association of vitamin D deficiency to different cardiovascular risk factors must be tested in well powered trials in future to evaluate for causality. Vitamin D deficiency is treatable and supplementation is inexpensive. With the evolving non-skeletal health benefits of vitamin $D$, it could be potentially considered as an important prophylactic measure to prevent cardiovascular morbidity and mortality in high-risk patients.

\section{ACKNOWLEDGEMENTS}

We are indebted to the entire faculty of Department of Cardiology, Department of Internal Medicine, and Department of Biochemistry, BPKIHS, for their continuous guidance and support during this study.

Conflict of Interest: None.

\section{REFERENCES}

1. Pilz S, Tomaschitz A, Drechsler C, Dekker JM, März W. Vitamin D deficiency and myocardial diseases. Mol Nutr Food Res. 2010 Aug;54(8):1103-13. [PubMed | Full Text | DOI]

2. Milazzo V, De Metrio M, Cosentino N, Marenzi G, Tremoli E. Vitamin D and acute myocardial infarction. World J Cardiol. 2017 Jan 26;9(1):14-20. [PubMed | Full Text $\mid$ DOI]

3. Mozos I, Marginean O. Links between vitamin D deficiency and cardiovascular diseases. Biomed Res Int. 2015 Oct;2015:109275. [PubMed $\mid$ Full Text $\mid \underline{\text { DOI] }}$
4. Karur S, Veerappa V, Nanjappa MC. Study of vitamin D deficiency prevalence in acute myocardial infarction. Int J Cardiol Heart Vessels. 2014 Mar 19;3:57-9. [PubMed | Full Text $\mid$ DOI]

5. Akhtar T, Aggarwal R, Jain SK. Serum vitamin D level in patients with coronary artery disease and association with sun exposure: experience from a tertiary care, Teaching Hospital in India. Adv Med. 2019 Feb 3;2019:6823417. [PubMed $\mid$ Full Text $\mid$ DOI]

6. Al Mheid I, Patel RS, Tangpricha V, Quyyumi AA. Vitamin 
$\mathrm{D}$ and cardiovascular disease: is the evidence solid?.Eur Heart J. 2013 Dec 21;34(48):3691-8. [PubMed | Full Text | DOI]

7. Lee JH, O'Keefe JH, Bell D, Hensrud DD, Holick MF. Vitamin D deficiency: an important, common, and easily treatable cardiovascular risk factor?. J Am Coll Cardiol. 2008 Dec 9;52(24):1949-56. [uㅏMed | Full Text | DOI]

8. Kassi E, Adamopoulos C, Basdra EK, Papavassiliou AG. Role of vitamin D in atherosclerosis. Circulation. 2013 Dec 3;128(23):2517-31. [ [PubMed | Full Text | DOI]

9. Dziedzic EA, Gąsior JS, Pawłowski M, Wodejko-Kucharska B, Saniewski T, Marcisz A, et al. Vitamin D level is associated with severity of coronary artery atherosclerosis and incidence of acute coronary syndromes in non-diabetic cardiac patients. Arch Med Sci. 2019 Mar;15(2):359-68. [PubMed $\mid$ Full Text $\mid$ DOI]

10. Lim S, Shin H, Kim MJ, Ahn HY, Kang SM, Yoon JW, et al. Vitamin D inadequacy is associated with significant coronary artery stenosis in a community-based elderly cohort: the Korean longitudinal study on health and aging. J Clin Endocrinol Metab. 2012 Jan 1;97(1):169-78. [PubMed |

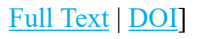

11. Roy A, Lakshmy R, Tarik M, Tandon N, Reddy KS, Prabhakaran D. Independent association of severe vitamin D deficiency as a risk of acute myocardial infarction in Indians. Indian Heart J. 2015 Jan 1;67(1):27-32. [PubMed | Full Text | DOI]
12. Martins D, Wolf M, Pan D, Zadshir A, Tareen N, Thadhani R, et al. Prevalence of cardiovascular risk factors and the serum levels of 25-hydroxyvitamin D in the United States: data from the Third National Health and Nutrition Examination Survey. Arch Intern Med. 2007 Jun 11;167(11):1159-65. [PubMed $\mid$ Full Text $\mid$ DOI]

13. Mathieu C, Waer M, Laureys J, Rutgeerts O, Bouillon R. Prevention of autoimmune diabetes in NOD mice by 1,25 dihydroxyvitamin D3. Diabetologia. 1994 Jun 1;37(6):552-8. [PubMed $\mid$ Full Text $\mid$ DOI]

14. Vaidya A, Forman JP. Vitamin D and hypertension: current evidence and future directions. Hypertension. 2010 Nov 1;56(5):774-9. [ PubMed $\mid$ Full Text $\mid$ DOI]

15. Rejnmark L, Vestergaard P, Heickendorff L, Mosekilde L. Simvastatin does not affect vitamin d status, but low vitamin $\mathrm{d}$ levels are associated with dyslipidemia: results from a randomised, controlled trial. Int J Endocrinol. 2010 Jan 1;2010. [PubMed $\mid$ Full Text $\mid$ DOI]

16. Gupta A. Vitamin D deficiency in India: prevalence, causalities and interventions. Nutrients. 2014 Feb 21;6(2):729-75. [ PubMed $\mid$ Full Text $\mid$ DOI]

17. Poudel N, Dhakal SS, Sukhupayo R, Karki DB. Vitamin D Deficiency among Patients Visiting a Tertiary Care Hospital: A Descriptive Cross-sectional Study. J Nepal Med Assoc. 2020 Nov;58(231):839. [Full Text | DOI] 